\title{
Cell death rocks
}

\section{Arjan W. Griffioen ${ }^{1} \cdot$ Patrycja Nowak-Sliwinska ${ }^{2}$}

Published online: 20 March 2019

(c) Springer Science+Business Media, LLC, part of Springer Nature 2019

An increasing number of scientific reports on the mechanisms of cell death is seeing light. Especially publications on the different processes of programmed cell death are getting major attention. For example, insight has been provided in the interaction between linear ubiquitination, regulators of cell death and type I interferon responses by OTULIN, thereby limiting cell death and inflammation [1]. Another important finding shows insight in the regulation of RNA decay in cells. This appears to be regulated by release of the mitochondrial intermembrane space 3 '-5'-exoribonuclease PNPT1 during apoptosis [2]. In a large cohort of early stage invasive breast cancer patients it was found that caspase-3 expression was associated to adverse cancer-specific survival [3]. The impact of these observations underline that it is of extreme importance to understand the mechanisms of cell death, in order to understand e.g. the mechanisms of disease. These observations also clearly demonstrate that cell death lives.

\section{From the editors' desks}

To better being able to serve the scientific community, the publisher and editors have embarked on a track to rejuvenate Apoptosis and implement a few changes to the appearance of the journal [4]. First of all, we decided to use of an award winning image on cell death for the cover of the journal. Last year's cover was an image provided by Dr. Ivan Poon (Victoria, Australia) showing the beaded apoptopodia of an ultraviolet light treated monocytic cell [5, 6]. The 2019 volume

Arjan W. Griffioen

aw.griffioen@vumc.nl

$\triangle$ Patrycja Nowak-Sliwinska

Patrycja.Nowak-Sliwinska@unige.ch

1 Angiogenesis Laboratory, Department of Medical Oncology, VU University Medical Center, 1081 HV Amsterdam, The Netherlands

2 School of Pharmaceutical Sciences, University of Geneva, University of Lausanne, Geneva, Switzerland will be covered by a dramatic electron microscopy image of an apoptotic cell, contributed by Dr. Walter Malorni and Dr. Antonella Tinari. This picture represents an MDCK dog kidney cell infected with influenza virus strain WSN and treated with the caspase inhibitor z-Vad [7, 8]. Infection of a cell by influenza A virus leads to apoptotic cell death. However, elevated lysosomal activity and an abundance of autophagosomes can be observed when apoptosis is inhibited. Hence, the balance between apoptotic mechanisms and autophagic cytoprotection pathway is essential for successful viral spreading or its abortive replication. On the cell side, apoptotic cell death or autophagic cell survival can in turn be pivotal in the pathogenetic mechanisms of infection. General processes occurring during apoptosis, such as cell surface blebbing, viral budding from the cell membrane and chromatin marginalization are clearly visible in the new cover image $[9,10]$.

Another change to the journal is that we reduced the number of accepted manuscripts and joined two issues together in one printed release. We hope that these measures will lead to increased recognition and impact of Apoptosis. Finally, a small market survey in the field indicated that the journal name Apoptosis may limit the scope of the journal, despite the provided subtitle An International Journal on Programmed Cell Death. The result of this survey started a discussion on a possible name change of the journal in the future.

\section{The editors' choice}

The general interest in research on cell death is also visible in the submissions to Apoptosis. The majority of submitted papers represent the fields of cardiovascular disease and cancer, where it is clear that cell death processes play key roles in the pathology of the disease.

A number of recently published papers should be highlighted. It was found that the mechanism by which diallyl trisulfide protects against apoptosis during myocardial 
ischemia-reperfusion injury in diabetic disease, involves activation of silent information regulator-1 (SIRT1) [11]. Another paper related to cardiovascular disease reports on the role of stromal cell-derived factor-1 (SDF-1) in stimulating TNF-mediated apoptosis in cardiac myocytes. Isolated rat cardiac myocytes treated with SDF-1 undergo apoptosis, suggesting the importance of SDF-1 in regulating the cardiomyocyte response to stress conditions [12]. In the field of cancer several submissions to the journal stood out. One paper reported on the pentahydroxyflavone Quercetin to induce protective autophagy and apoptosis via the STAT3/Bcl-2 pathway in ovarian cancer cells. The authors suggested that this finding provides a new angle to circumvent drug resistance in patients by targeting protective autophagy pathways [13]. Another interesting paper reports on the promotion of cytotoxic autophagy and apoptosis in phenotypically different breast cancer cells by affecting the glycolytic pathway by ursolic acid [14]. In cervical cancer HeLa cells it was shown that piperazine suppresses proliferation and migration, but induced apoptosis. This paper suggested a new compound for the development of an effective antitumor agent [15]. Apoptosis also published a number of excellent reviews as well. Rathore et al. published on the bypassing drug resistance in cancer by targeting inhibitors of apoptosis proteins (IAPs). In this paper mimetics of second mitochondriaderived activator of caspase (SMAC) are highlighted as potential agents to treat cancer [16]. Circumvention of negative regulators of cell death is a major challenge in cancer research, as these molecules can be important in the development of drug induced resistance. A review by Razaghi et al. presents this potential arena for drug discovery and biomarker development [17]. Another paper reviews the strategies of inducing reactive oxygen species in cancer cells, as an approach for anticancer therapy [18]. Outside the field of cancer two excellent reviews were published. One of these was on the role of endoplasmic reticulum (ER) stress in neurodegenerative disease. Unfolded protein response is a cellular response to ER stress. Dysfunction of this process plays an important role in the pathogenesis of Alzheimer's disease, Parkinson's disease, amyotrophic lateral sclerosis and Huntington's disease by the accumulation and aggregation of misfolded proteins. It is suggested that inhibition of specific ER mediators may contribute to the treatment and prevention of neurodegeneration [19]. Last but not least to mention is the paper that reviews the apoptosis-induced lymphopenia in sepsis and severe injuries. These conditions are usually followed by a period of marked immunosuppression. It is suggested that apoptosis targeting strategies can be applied to intervene in patients with such conditions [20]. Apoptosis will continue the effort of publishing high-impact publications.

\section{References}

1. Heger K, Wickliffe KE, Ndoja A, Zhang J, Murthy A, Dugger DL, Maltzman A, de Sousa EMF, Hung J, Zeng Y, Verschueren E, Kirkpatrick DS, Vucic D, Lee WP, Roose-Girma M, Newman RJ, Warming S, Hsiao YC, Komuves LG, Webster JD, Newton K, Dixit VM (2018) OTULIN limits cell death and inflammation by deubiquitinating LUBAC. Nature 559:120-124

2. Liu X, Fu R, Pan Y, Meza-Sosa KF, Zhang Z, Lieberman J (2018) PNPT1 release from mitochondria during apoptosis triggers decay of poly(A) RNAs. Cell 174:187-201.e12

3. Pu X, Storr SJ, Zhang Y, Rakha EA, Green AR, Ellis IO, Martin SG (2017) Caspase-3 and caspase- 8 expression in breast cancer: caspase-3 is associated with survival. Apoptosis 22:357-368

4. Griffioen AW, Nowak-Sliwinska P (2017) Apoptosis turns 21. Apoptosis 22:1485-1486

5. Nowak-Sliwinska P, Griffioen AW (2018) Apoptosis on the move. Apoptosis 23:251-254

6. Atkin-Smith GK, Tixeira R, Paone S, Mathivanan S, Collins C, Liem M, Goodall KJ, Ravichandran KS, Hulett MD, Poon IK (2015) A novel mechanism of generating extracellular vesicles during apoptosis via a beads-on-a-string membrane structure. Nat Commun 6:7439

7. Datan E, Shirazian A, Benjamin S, Matassov D, Tinari A, Malorni W, Lockshin RA, Garcia-Sastre A, Zakeri Z (2014) mTOR/ p70S6K signaling distinguishes routine, maintenance-level autophagy from autophagic cell death during influenza A infection. Virology, 452-453:175-190

8. Degli Esposti M, Matarrese P, Tinari A, Longo A, Recalchi S, Khosravi-Far R, Malorni W, Misasi R, Garofalo T, Sorice M (2017) Changes in membrane lipids drive increased endocytosis following Fas ligation. Apoptosis 22:681-695

9. Tinari A, Giammarioli AM, Manganelli V, Ciarlo L, Malorni W (2008) Analyzing morphological and ultrastructural features in cell death. Methods Enzymol 442:1-26

10. Giammarioli AM, Gambardella L, Barbati C, Pietraforte D, Tinari A, Alberton M, Gnessi L, Griffin RJ, Minetti M, Malorni W (2012) Differential effects of the glycolysis inhibitor 2-deoxyD-glucose on the activity of pro-apoptotic agents in metastatic melanoma cells, and induction of a cytoprotective autophagic response. Int J Cancer 131:E337-E347

11. Yu L, Li S, Tang X, Li Z, Zhang J, Xue X, Han J, Liu Y, Zhang Y, Zhang Y, Xu Y, Yang Y, Wang H (2017) Diallyl trisulfide ameliorates myocardial ischemia-reperfusion injury by reducing oxidative stress and endoplasmic reticulum stress-mediated apoptosis in type 1 diabetic rats: role of SIRT1 activation. Apoptosis 22:942-954

12. Jarrah AA, Schwarskopf M, Wang ER, LaRocca T, Dhume A, Zhang S, Hadri L, Hajjar RJ, Schecter AD, Tarzami ST (2018) SDF-1 induces TNF-mediated apoptosis in cardiac myocytes. Apoptosis 23:79-91

13. Liu Y, Gong W, Yang ZY, Zhou XS, Gong C, Zhang TR, Wei X, Ma D, Ye F, Gao QL (2017) Quercetin induces protective autophagy and apoptosis through ER stress via the p-STAT3/Bcl-2 axis in ovarian cancer. Apoptosis 22:544-557

14. Lewinska A, Adamczyk-Grochala J, Kwasniewicz E, Deregowska A, Wnuk M (2017) Ursolic acid-mediated changes in glycolytic pathway promote cytotoxic autophagy and apoptosis in phenotypically different breast cancer cells. Apoptosis 22:800-815

15. Khanam R, Kumar R, Hejazi II, Shahabuddin S, Meena R, Jayant V, Kumar P, Bhat AR, Athar F (2018) Piperazine clubbed with 2 -azetidinone derivatives suppresses proliferation, migration and induces apoptosis in human cervical cancer HeLa cells through oxidative stress mediated intrinsic mitochondrial pathway. Apoptosis 23:113-131 
16. Rathore R, McCallum JE, Varghese E, Florea AM, Busselberg D (2017) Overcoming chemotherapy drug resistance by targeting inhibitors of apoptosis proteins (IAPs). Apoptosis 22:898-919

17. Razaghi A, Heimann K, Schaeffer PM, Gibson SB (2018) Negative regulators of cell death pathways in cancer: perspective on biomarkers and targeted therapies. Apoptosis 23:93-112

18. Zou Z, Chang H, Li H, Wang S (2017) Induction of reactive oxygen species: an emerging approach for cancer therapy. Apoptosis 22:1321-1335

19. Xiang C, Wang Y, Zhang H, Han F (2017) The role of endoplasmic reticulum stress in neurodegenerative disease. Apoptosis 22:1-26
20. Girardot T, Rimmele T, Venet F, Monneret G (2017) Apoptosisinduced lymphopenia in sepsis and other severe injuries. Apoptosis 22:295-305

Publisher's Note Springer Nature remains neutral with regard to jurisdictional claims in published maps and institutional affiliations. 